\title{
PROJECT SUMMARY - 54680 \\ THE MIGRATION AND ENTRAPMENT OF DNAPLS IN PHYSICALLY AND CHEMICALLY HETEROGENEOUS POROUS MEDIA
}

March 1, 2000

\author{
DRS. LINDA M. ABRIOLA AND AVERY H. DEMOND \\ The University of Michigan \\ Department of Civil and Environmental Engineering \\ Ann Arbor, Ml 48109-2125 \\ abriola@engin.umich.edu; averyd@engin.umich.edu
}

Research Personnel: An assistant research scientist and three graduate students

\section{RESEARCH OBJECTIVE}

This document summarizes EMSP funded research designed to improve our understanding of and ability to simulate the influence of subsurface chemical heterogeneities on DNAPL flow and entrapment in the saturated zone. Specific project objectives include: (i) the quantification of DNAPL interfacial and hydraulic properties; (ii) development and assessment of constitutive hydraulic property and continuum based multiphase flow models; (iii) exploration of DNAPL migration and entrapment in heterogeneous systems at larger scales; and (iv) development of innovative remediation schemes.

\section{RESEARCH PROGRESS AND IMPLICATIONS}

A series of experiments has been conducted to explore the influence of representative surface-active agents, dodecylamine (DDA) and octanoic acid (OA), on interfacial properties in PCE-water-quartz systems. DDA and OA exhibit pH dependent acid-base speciation in aqueous solution, resulting in aqueous chemistry-dependent interfacial tension and/or wettability in these systems. When the neutral species of DDA $(\mathrm{pH}>10.6)$ and $\mathrm{OA}(\mathrm{pH}<4.8)$ was dominant, minimal changes to interfacial properties were observed because of preferential partitioning of DDA and OA into the NAPL. In contrast, the cationic form of DDA $(\mathrm{pH}<10.6)$ sorbed both to quartz and NAPLwater interface, altering the wettability from water-wet to neutral wettability and lowering the NAPLwater interfacial tension. The anionic form of $\mathrm{OA}(\mathrm{pH}>4.8)$ sorbed only to the NAPL-water interface, lowering the interfacial tension by as much as $50 \%$.

Additional experiments were designed to examine the influence of organic acids on the wetting properties of solid surfaces of varying mineralogy. Bottle tests were used to assess the wettability behavior of soils composed of quartz, iron oxide coated quartz, aluminum oxide coated quartz, limestone ( $\mathrm{CaCO} 3)$, and shale in the presence of a dyed mineral oil and various aqueous solutions ( $\mathrm{pH}=6.5$ ) of $\mathrm{OA}$ (the anionic form of $\mathrm{OA}$ dominates at $\mathrm{pH}=6.5)$. In the absence of $\mathrm{OA}$, all of the soils except the shale were observed to be strongly water-wet; i.e., the shale was partially NAPL-wet. In contrast, in the presence of $0.1 \mathrm{M} \mathrm{OA}$, only the quartz soil was water-wet; the soils composed of iron oxide coated quartz, aluminum oxide coated quartz, limestone, and shale were strongly NAPL-wet.

Experiments were conducted to explore the influence of solution chemistry of organic acids and bases on the capillary pressure relationship. The influence of OA and DDA concentration on the capillary pressure relationship for a tetrachloroethylene (PCE)-water-quartz system was examined and compared to previous results obtained for the same solutes in an o-xylene-waterquartz system. Despite the different properties of PCE and o-xylene, including polarity, aromaticity, density, and pure solvent interfacial tensions, the speciation, sorption and partitioning of the solutes were similar and influenced the capillary pressure relationship similarly. When the $\mathrm{pH}$ was above the pKa, OA is preferentially in an anionic form and, therefore, OA remains in the 
aqueous phase where it influences the interfacial tension to a greater extent. Hence, the capillary pressure at a particular aqueous phase saturation was observed to be lower at $\mathrm{pH}$ values above the pKa. A similar lack of dependence on the nature of the organic liquid phase was observed in the DDA-NAPL-water-quartz systems. In this case, however, capillary pressure relations were affected by $\mathrm{pH}$ dependent changes in both interfacial tension and solid wettability.

Additional research efforts have focused on the determination and quantification of hydraulic property relations for synthetic fractional wettability porous medium (systems composed of known water- and organic-wet fractions), and for media having uniform, well-defined, solid surface chemistries (quartz, Fe oxide coated quartz, Al oxide coated quartz, limestone, and shale). Results indicate that the magnitude and shape of the capillary pressure curves are strongly dependent on the fractional wettability of the system. As the DNAPL-wet fraction of a soil increases, for a given saturation and saturation history, the DNAPL-water capillary pressure decreases, becoming negative at higher water saturations. In the absence of surface active organic compounds, most soils having identical grain size distributions but different solid surface chemistry produced similar capillary pressure relations. After exposure to a $0.1 \mathrm{M}$ solution of $\mathrm{OA}(\mathrm{pH}=6.5)$ followed by prolonged rinses with Milli-Q water (approximately $50 \mathrm{PV}$ ), the hydraulic properties for some of these soils exhibited a much more pronounced variation in wettability depending upon the soil's solid surface characteristics. Recall that wettability bottle test for these soils demonstrated that iron oxide coated quartz, aluminum oxide coated quartz, limestone, and shale were strongly NAPL-wet in the presence of $0.1 \mathrm{M} \mathrm{OA}$ and mineral oil. Additional measurements of hydraulic property relations for these soils in the presence of various OA concentrations are planned.

For the soils with well defined fractional wettability and solid surface chemistry, transient outflow measurements were undertaken with the automated setup that was used to determine capillary pressure relations. This transient information is currently being used to determine relative permeability relations according to history matching procedures. Due to the inability of previously developed multiphase models to handle the measured time dependent water and DNAPL pressure boundary conditions, a new one-dimensional multiphase flow simulator has been developed to solve the direct problem (simulation of outflow data). This simulator has been successfully coupled with a nonlinear least-squares fitting routine to solve the indirect problem (optimize hydraulic property model parameters to the outflow data).

Residual water and DNAPL saturations were also found to systematically vary as a function of fractional wettability. The magnitude of residual DNAPL saturations varied by 52 to $80 \%$ for the experimental sands as wettability was altered. The residual organic saturation in finer textured sands reached a minimum at intermediate wetting conditions, whereas residual saturations in coarser textured soils decreased asymptotically with increasing fraction of organicwet sand. These observations were explained in terms of plausible interactions between NAPL films and ganglia, and surface area considerations. For media with NAPL-wet solids, an inverse correlation of residual organic saturation with grain size can be easily explained in terms of the relationship between increasing solid surface area and decreasing permeability.

The Pl's have adapted a two-dimensional multiphase flow simulator to explore the influence of coupled physical and chemical heterogeneity on DNAPL migration and entrapment in the saturated zone. For reasonable ranges of wettability characteristics, simulations suggest that spatial variations in wettability can have a dramatic impact on DNAPL distributions. In physically homogeneous coarse textured systems, increasing the contact angle or organic-wet fraction of a soil produced a prolonged slow migration of the DNAPL, creating larger contaminated aquifer regions with lower organic saturations. In coupled physically and chemically heterogeneous systems, interfaces of capillary property contrast (soil texture or soil wettability) led to higher organic saturations, increased lateral spreading, and decreased depths of organic liquid infiltration.

Based upon findings from these numerical studies, experimental research has been initiated in two-dimensional sand boxes to explore the coupled influence of physical and chemical heterogeneity on DNAPL migration and entrapment. Subsurface wettability characteristics were demonstrated to have a dramatic influence on DNAPL migration and entrapment. DNAPL-wet layers were shown to behave as a very effective capillary barrier, retaining DNAPL and inhibiting its 
downward migration until the layer became saturated with DNAPL. Subsequent experimental studies with this setup were conducted to assess the ability of DNAPL-wet layers to contain mobilized DNAPL during surfactant flushing. Results from this study suggests that wettability alteration could be used in conjunction with other remediation schemes to improve their efficiency and performance. Hydraulic properties of the soils utilized in the two-dimensional infiltration studies discussed above have been measured. This information, in conjunction with the developed multiphase simulator, is currently being used to assess the ability of this simulator to predict observed DNAPL infiltration and redistribution behavior. The sand box observations are also being used to further refine constitutive hydraulic property models and to explore scale-up issues in modeling multiphase systems.

\section{PLANNED ACTIVITIES}

The project completion date for this grant is September 14, 2000. Research efforts that are currently underway were identified above. Upon completion of these studies, efforts will be directed towards data analysis and the writeup of research findings.

\section{INFORMATION ACCESS}

Bradford, S. A., L. M. Abriola, and F. J. Leij. 1999. Multi-fluid hydraulic properties for fractional wettability porous media. In: Characterization and Measurement of the Hydraulic Properties for Unsaturated Porous Media (Editors, M.Th. van Genuchten, F.J. Leij and L. Wu), University of California, Riverside, (In press).

Bradford, S. A., and L. M. Abriola. 1998. Entrapment and dissolution of organic liquids in chemically heterogeneous porous media. In: IAHS Publication no. 250, Groundwater Quality: Remediation and Protection, Tubingen, Germany, pp. 167-172.

Bradford, S. A., L. M. Abriola, and K. M. Rathfelder. 1998a. Flow and entrapment of dense nonaqueous phase liquids in physically and chemically heterogeneous aquifer formations. Adv. Water Res., 22:117-132.

Bradford, S. A., L. M. Abriola, and K. M. Rathfelder. 1998b. Simulated entrapment and dissolution of organic liquids in chemically heterogeneous porous media. In: Enviromeet 98- Behavior and Remediation of Nonaqueous Phase Contaminants in the Subsurface (Editors C.V. Chrysikopoulos, J. Bear, and T. C. Harmon), University of California, Irvine, pp. 7-16.

Bradford, S. A., L. M. Abriola, and F. J. Leij. 1997. Wettability effects on two- and three- fluid relative permeabilities. J. Contam. Hydrol., 28, 171-191.

Demond, A.H., K.F. Hayes, D.L. Lord, F. Desai and A. Salehzadeh. 1999. Impact of organic compound chemistry on capillary pressure relationships of sands. In: Characterization and Measurement of the Hydraulic Properties for Unsaturated Porous Media (Editors, M.Th. van Genuchten, F.J. Leij and L. Wu) University of California, Riverside, (In press).

Lord, D.L. 1999. Influence of organic acid and base solution chemistry on interfacial and transport properties of mixed wastes in the subsurface. Ph.D. dissertation. Department of Civil and Environmental Engineering, The University of Michigan, Ann Arbor, MI.

Lord, D.L., A.H. Demond, K.F. Hayes, and A. Salehzadeh. 1999. Effects of surfactant chemistry on interfacial tension, wettability, and capillary pressure in multiphase subsurface waste systems, Transport in Porous Media, in press.

Lord, D. L., K. F. Hayes, A. H. Demond, and A. Salehzadeh. 199a. Influence of organic acid solution chemistry on subsurface transport properties. 1. Surface and interfacial tension. Environ. Sci. Technol., 31, 2045-2051.

Lord, D. L., A. H. Demond, A. Salehzadeh, and K. F. Hayes. 199b. Influence of organic acid solution chemistry on subsurface transport properties. 2. Capillary pressure- saturation. Environ. Sci. Technol., 31, 2052-2058.

Web Sites: http://www-personal.engin.umich.edu/ abriola http://www-personal.engin.umich.edu/ sbrad 